\title{
Cesarean section surgeries: the temporal evolution, epidemic tendency, the WHO proposals and recommendations, current doubts and challenges
}

\author{
Malaquias Batista Filho 1 \\ Camila Carvalho dos Santos 2 \\ 1 Instituto de Medicina Integral Prof. Fernando Figueira. Rua dos Coelhos, 300. Boa Vista. Recife, PE, Brasil. CEP: 50.070-902. \\ E-mail: malaquias.imip@gmail.com \\ 2 Programa de Pós Graduação em Enfermagem Obstétrica. Instituto de Medicina Integral Prof. Fernando Figueira. Recife, PE, Brasil.
}

In addition to the last century (1985), the World Health Organization (WHO) promoted an international meeting in Brazil to analyze and propose recommendations on the emerging problem that was already a great concern, cesarean surgeries quickly replacing the ancient practice of natural birth. The meeting mobilized professionals, researchers and statistical information from a few countries, establishing consensus and principles that should be adjusted for the purpose and that 10 to $15 \%$ of the cesarean sections would be an international reference for the use of surgical childbirths at a populational level as prescribed as a known risky situation for the pregnant woman or the fetus. 1

The WHO held a much more ambitious international meeting to consolidate information, analysis and recommendations on the clear and serious epidemic situation of the cesarean surgeries ${ }^{2}$ after 30 years in Fortaleza (2015). At the event, the WHO defined a set of reasons and observations in order to face the epidemic process of cesarean sections and proposed the use of Robson Classification ${ }^{3}$ as a tool to monitor and compare the cesarean section rates. ${ }^{2}$

A group of researchers consolidated data and estimates from 150 countries in the referring period of 1990-2014. Beside the continuous tendency in cesarean section rates in countries joined by the United Nations health regions, it concluded that $18.6 \%$ of all the births appealed to cesarean interventions ranged from $6 \%$ to $27.2 \%$ in the analysis period with great differences among the regions (Latin America and the Caribbean 40.3\%, Asia 19.2\% and Africa 7.3\%). Brazil (55.4\%) and the Dominican Republic (56.4\%) were the countries with the highest rate in the world. Undoubtedly, this result of heterogeneity is a challenge in searching for purposes and to apply political agreement strategies, programs and actions in various countries. 4

Ye et al. 5 study included longitudinal data from 159 countries representing $98 \%$ of the total births becoming a notable document of descriptive and analytical information on cesarean section at a populational level and the most common outcomes on maternal and neonatal mortality. In some countries, the rates have increased more than five times since the WHO recommended the $10-15 \%$ as the most appropriate purpose to minimize maternal and neonatal mortality. In fact, the ecological evidence is that the rates, higher than $10 \%$, did not correlate with the best responses, which would then be altered by the human development indices of the countries. The adjustments in the regression models induce that the optimization of the responses would occur within the cesarean rates between $5-10 \%$ or below. 5

A systematic review on ecological studies performed by Betran et al., 6 started from 11,832 singular quotes published between 2000 and 2014, making it very clear that cesarean interventions continued to be increasing. Eight studies were selected dealing with a possible association between 
rates em relation to mothers and children having as a maternal and neonatal mortality outcomes. At the final selection, seven articles correlated cesarean sections with maternal mortality rates, five with neonatal mortality, four with infant mortality, two with low birth weight (LBW) and one with fetal death. An exception of one, all of them were crosssectional studies, one was a global analysis, two correlated socioeconomic factors and none reported clinical data or the population's demographic characteristics. 6

In Brazil, one of the most relevant and revealing studies on a possible relation between the increase on cesarean rates was the analysis of $2,903,716$ hospital births registered in all the hospitals in the country during 2015 representing more than $96 \%$ of the births. ${ }^{7}$ The prevalence of $55.5 \%$ of the cesarean sections was analyzed according to various biological, socio-environmental conditions and pregnancy duration with a pre-term prevalence of $10.1 \%$. It concluded that Brazil experiences three interrelated epidemics: one on cesarean section surgeries, a second on preterm births related to the first and a third on prematurity attributable mainly on the poverty condition. 7 This distribution, may perhaps be applied to the diversity of isolated or a combination of risk factors in various other countries and regions.

In 2018, considering the purposes on the Sustainable Development for the millennium (to ensure healthy life and promote well-being for everyone of all ages), and in this context, the new global strategies for women, children and adolescents' health, the WHO expands its focus, in not risking anymore in mothers and children's survival in a brief and critical pregnancy/childbirth period, but for the purpose to be effective and to reach the potential growth and development. This is a much more comprehensive and integral dimension. ${ }^{8}$

Preceded by a comment from our co-authors ${ }^{9}$ at the Brazilian Journal of Mother and Child Health (BJMCH) highlighted a number of striking observations in the WHO document by introducing a short text in the "Letter to the Editor" by Sergei Jargin, a Russian researcher (University of Moscow), published in the BJMCH. ${ }^{10}$ In regard to this letter, our position presented in this edition, forming a set of three thematically related assessments.

Representing the Dominican Republic, the highest rates of cesarean interventions in the world (about $55 \%$ of all births), Brazil is assuming a central role in the evolution of the cesarean section problem in a concerning epidemiological level. 4 Promisingly, last year (2017), Brazil presented a favorable reaction with a reduction of $1.5 \%$ on the cesarean section rates. 11

It is acknowledged that Professor Jargin 10 made some important considerations on the cesarean section issue especially if the tubal ligation was combined as a choice that met the demographic policy purposes, the economic costs and even the new and instigated epidemiological tendency that were being evidenced in countries such as China and India. In fact, these two countries present remarkable imbalance in relation to men/women at birth, with an increased rate on male births, a tendency that is reproduced in other countries quoted by the author. ${ }^{12-14}$ According to Jargin, this increase correlates with the rise of multiparity which is notable among pregnant women's higher age group. 10

It is worth to compare two other populational events of the opposite direction that it is reduced, rebalanced or may even reversed in a worldwide level: the highest mortality is of male children in the first days and months of life and especially in adulthood and the elderly, in a way, that at the end, the hope for life at birth for women is about $10 \%$ higher than men. 15 This expresses that at the end of the vital cycle, a difference of 7 to 8 years disfavors men. In other words, according to these data, the imbalanced demographic does not justify as an adverse outcome. It is evident that from the aspect of the collective health, higher percentages of great parity and simultaneously or not, correlating the increased age in the gravid period representing its own expressive risk for the woman and the fetus.

These observations are consensual but as an extent indicating a certain rudeness (death versus survival) does not account on other potential manifestations to other near outcomes or above all, remote on what would happen to the cohorts or other types that accompany among those that will be born or not under cesarean sections in comparable conditions. In other words, they are either equalized or controlled by other variables that may confound the late effects of surgical intervention. These are questions that accumulate to underlie the advantages or on the contrary, the undesirable effects of cesarean surgery. And even more, it is conjugated to the tubal ligation which leads to sterilization, preventing recurrence of new pregnancies and, therefore, the risks increase by surgery or by the anesthesia of new cesarean sections.

The letter from Dr. Jargin 10 is very enlightening in this regard, when simply occurres a formal logic, besides many other benefits or adverse effects which are decided by the statistic logic material applied on controlled studies. There is also a growing number 
of questions and, above all, the doubts on public policies that may stimulate high fertility rates, as a "protectionist" measurement of poor and numerous families. And evidently, these are windows of analysis that differ in pros and cons from the ideological perspectives of different authors in different contexts.

In Brazil, the demographic aspects are singularly clear, the estimated fertility rates for the whole country fell from 2.32 to 1.80 between 2000 and 2015. At the macro-regional level (North, Northeast, Southeast, South and Midwest) all the fertility rates, except for the North region, the decline was below 1.90 per year, perhaps reaching 1.76 for the whole country by 2020.16 Therefore, within the next two years, the Brazilian population may cease to increase and tend to decrease. Thus, the current tendencies and future projections are of no concern. Singular case in some countries would have residual issues, such as the overall rates or specific minority sector rates in national contexts, as the case of understudying "favelas" (slums) or sub-normal urban agglomerations in Brazil, where 11 million people still live deprived of their rights and are attributed to their citizenship. 1770 years ago, Josué de Castro already admitted that the regulation of demographic growth is an achievement on economical and social development, but not the contrary. In the future, the solution would be called human development.

In addition to the issue of birth control and whether or not the dilemma will survive, in which it is a fact, a reductionism, and in the possible bias which is still not clear on other factors that would act in the determination of the mother and the child's death, it relates to other arguments, such as reducing the risk of serous ovarian carcinoma and endometrioid carcinoma, beside a possible positive role in sexuality. These facts would be properly assessed, useful regarding to the risk of mortality and other positive or adverse effects that have not, so far, been accounted for in the evaluation of major international events on normal births, cesarean sections and instigated option for tubal ligation. These are our and Professor Sergei Jargin questionings which could be included in the panel for future events and in the guidelines on normal childbirth and surgical interventions, including whether or not the physician/client has an option on surgical solutions, which sets a wide range of conflicting issues, especially in the ethical field.

\section{References}

1. Appropriate technology for birth. Lancet. 1985; 2 (8452): 436-7.

2. World Health Organization Human Reproduction Programme. WHO Statement on caesarean section rates Reprod Health Matters. 201523 (45): 149-50.

3. Robson MS. Classification of caesarean sections. Fetal and Maternal Medicine Review. 2001; 12 (1): 23-39.

4. Betran AP, Ye J, Moller A-B, Zhang J, Gülmezoglu AM, Torloni MR. The Increasing Trend in Caesarean Section Rates: Global, Regional and National Estimates: 1990 2014. PLoS One. 2016; 11 (2): e0148343.

5. Ye J, Zhang J, Mikolajczyk R, Torloni MR, Gulmezoglu AM, Betran AP. Association between rates of caesarean section and $€$ maternal and neonatal mortality in the $21 \mathrm{st}$ century: a worldwide population-based ecological study with longitudinal data. BJOG 2016; 123: 745-53.

6. Betran AP, Torloni MR, Zhang J, Ye J, Mikolajczyk R, Deneux-Tharaux C, Oladapo OT, Souza JP, Tunçalp Ö, Vogel JP, Gülmezoglu AM. What is the optimal rate of caesarean section at population level? A systematic review of ecologic studies. Reprod Health. 2015; 12 (1): 57.

7. Barros FC, Rabello Neto DdL, Villar J, Kennedy SH, Silveira MF, Diaz-Rosselo JD Victora CG. Caesarean sections and the prevalence of preterm and early-term births in Brazil: secondary analyses of national birth registration. BMJ Open. 2018; 8: e021538.

8. WHO recommendations: intrapartum care for a positive childbirth experience. Geneva: World Health Organization; 2018. Licence: CC BY-NC-SA 3.0 IGO.

9. Filho MB, Rissin A. WHO and the epidemic of cesarians. Rev Bras Saúde Mater Infant. 2018; 18 (1): 3-4.

10. Jargin SV. Cesariana combinada com esterilização tubária: alguns aspectos médicos e demográficos. Rev Bras Saúde Mater Infant. 2018; 18 (3): 677-9.

11. Brasil. Ministério da Saúde. Pela primeira vez número de cesarianas não cresce no país. [acesso em 10 out 2018]. Disponível em: http://portalms.saude.gov.br/noticias/ agencia-saude/27782-pela-primeira-vez-numero-de-cesarianas-nao-cresce-no-pais.

12. Huang Y, Tang W, Mu Y, Li X, Liu Z, Wang Y, Li M, Li Q, Dai L, Liang J, Zhu J. The sex ratio at birth for 5,338,853 deliveries in China from 2012 to 2015: a facility-based study. PLoS One. 2016; 11: e0167575.

13. Jargin SV. Overpopulation and modern ethics. S Afr Med J. 2009; 99: 572-3.

14. Jargin SV. Letter to the Editor. Int J Risk Saf Med. 2016; 28 (3): 171-4.

15. IBGE (Instituto Brasileiro de Geografia e Estatística). Diretoria de Pesquisas Coordenação de População e Indicadores Sociais. Tábua completa de mortalidade para o Brasil: breve análise da evolução da mortalidade no Brasil. Rio de Janeiro; 2017. 
16. IBGE (Instituto Brasileiro de Geografia e Estatística) Projeções da população: Brasil e Unidades da Federação: revisão 2018. 2 ed. Rio de Janeiro; 2018.

17. IBGE (Instituto Brasileiro de Geografia e Estatística) Censo Demográfico 2010. Aglomerados subnormais: informações territoriais. [acesso em 2 out 2018]. Disponível em: https://biblioteca.ibge.gov.br/visualizacao/periodicos/552/c d 2010 agsn if.pdf

Received on November 5, 2018

Approved on November 14, 2018 